\title{
Body Fat Distribution Measured by Bioelectrical Impedance Analysis is Associated with Occurrence of Colorectal Adenoma: A Case Control Study
}

\section{Zhong-Hui Liu}

University of Hong Kong-Shenzhen Hospital https://orcid.org/0000-0002-8604-4818

\section{Gui-Xi Zhang}

University of Hong Kong-Shenzhen Hospital

Hao Zhang

University of Hong Kong-Shenzhen Hospital

Li Jiang

University of Hong Kong-Shenzhen Hospital

Yang Deng

University of Hong Kong-Shenzhen Hospital

Jian-Wen Liu

University of Hong Kong-Shenzhen Hospital

Xue-Fei Yang

University of Hong Kong-Shenzhen Hospital

Fion Siu-Yin Chan

University of Hong Kong

Joe King-Man Fan ( $\nabla$ drjoefan@hku.hk)

https://orcid.org/0000-0001-6604-2295

\section{Research}

Keywords: visceral obesity, adenoma, colorectal, bioelectrical impedance

Posted Date: July 9th, 2020

DOl: https://doi.org/10.21203/rs.3.rs-40366/v1

License: (c) (i) This work is licensed under a Creative Commons Attribution 4.0 International License.

Read Full License 


\section{Abstract}

Objectives

Some studies have reported that visceral fat volume measured by computed tomography (CT) was a risk factor for colorectal adenoma (CRA). However, CT is not a good method for risk stratification in clinical use for its radiation. Bioelectrical impedance analysis (BIA) is a non-invasive method for assessment of body composition. The aim of current study was to evaluate the association of body fat measured by BIA with occurrence of CRA.

Patients and methods:

A total of 410 participants who had underwent screening colonoscopy from Jul 2017 to Dec 2019 in our center were recruited, including 230 with adenoma and 180 without adenoma detected. Body fat of participants were measured by BIA, including body fat mass (BFM), body fat percent (BFP), and waist-tohip fat ratio. Parameters of metabolic syndrome (MetS) were also measured, including waist circumference, blood pressure, fasting blood glucose, blood level of triglyceride, cholesterol and highdensity lipoprotein.

Results

According to univariate analysis, age, male proportion, BMI, waist circumference, body fat mass, waist-tohip fat ratio, blood pressure, and FBG were higher in adenoma group than adenoma-free group, $p<0.05$. On multivariate analysis (adjusted for age, sex, smoking, drinking, family history of CRC, etc.), High waistto-hip fat ratio measured by BIA was associated with occurrence of CRA (compared with normal waist-tohip fat ratio, OR $1.84 ; 95 \% \mathrm{Cl}, 1.09-3.09 ; \mathrm{p}=0.02$ ). High waist circumference, as a component of MetS, was also independently associated with CRA (OR 1.90; $95 \% \mathrm{Cl} 1.17-3.08, \mathrm{p}=0.01)$.

Conclusion

Body fat distribution measured by BIA is associated with occurrence of CRA. Central obesity is a risk factor for CRA.

Trial registration:

This study was prospectively registered in Chinese Clinical Trials Registry (www.chictr.org.cn; registry number: ChiCTR-RRC-17010862).

\section{Background}

Colorectal cancer (CRC) ranked globally the third for cancer incidence and fourth for cancer related death ${ }^{1}$. CRC is developed mainly from colorectal adenomatous polyps via pathway of adenomacarcinoma sequence and therefore, its prevention depends largely by early detection and removal of 
colorectal adenoma (CRA) ${ }^{2,3}$. It was reported that the incidence of CRC significantly decreased by 76$90 \%$ with endoscopic removal of $\mathrm{CRA}^{4}$. Screening colonoscopy and polypectomy will significantly reduce the incidence and mortality of $\mathrm{CRC}^{5}$. However, colonoscopy is a resource consuming and invasive investigation, which leads to discomfort and associates with risk of perforation. Screening colonoscopy is not universally done worldwide as its indications are still controversial. Identification of risk factors for CRA and establish screening program accordingly will probably increase yield and hence costeffectiveness of screening colonoscopy.

Obesity ${ }^{6}$, male, old age, smoking, and family history of $\mathrm{CRC}$ are known risk factors for $\mathrm{CRA}^{7}$. Despite increased risk of CRA observed in obese patients, the risk in these patients need be further stratified. With individual variations in body composition, in particular body fat distribution, patients of same body mass index (BMI) may suffer different degrees of risk of CRA. Visceral adiposity is supposed to be more harmful, and more predictive of risk for CRA than absolute body weight alone ${ }^{8}$. However, visceral adiposity is difficult to be precisely measured. Bioelectrical impedance analysis (BIA) is a simple, noninvasive and accurate method for measurement of body composition. In this case control study, we investigate the relationship between incidence of CRA with body fat measured by BIA.

\section{Methods}

\section{Study design and study population}

Colonoscopy and pathology reports for asymptomatic patients aged between 18 and 80 years who underwent colonoscopy at the University of Hong Kong-Shenzhen Hospital from July 2017 to December 2019 were screened for eligibility for participation in this study. Patients were excluded if they had poor bowel preparation, incomplete colonoscopy, history of colonic polypectomy or colectomy; or findings of colonic polyposis, colitis or $\mathrm{CRC}$ in the index colonoscopy. The enrolled participants were assigned into two groups according to the colonoscopy and pathology findings: adenoma group and adenoma-free group. The adenoma group consisted of patients who had one or more colorectal adenomas (including tubular or villous adenoma with or without dysplasia). The adenoma-free group consisted of subjects without adenoma. Patients with hyperplastic polyps were included in the adenoma-free group.

Sample size estimation: The main study parameter of this study is waist-to-hip fat ratio. In a large-scale prospective study including 1045 participants with adenoma and 2877 participants of normal control conducted in Korea in year $2010^{9}$, waist-to-hip ratio were 0.91 (SD 0.07) in adenoma group compared to 0.88 (SD 0.08) in normal control group. We estimated the sample size by calculating these data in formula $\left(n=2\left(\mu_{a}+\mu_{\beta}\right)^{2} * \sigma^{2} / \delta^{2}, a=0.05 ; \beta=0.1 ; \mu_{a}\right.$ (bilateral) $=1.960 ; \mu_{\beta}$ (bilateral) $\left.=1.6449\right)$, and the estimated sample size was at least 163 in each group.

We screened from 1849 patients aged between 18 and 80 years, who are parts of patients underwent colonoscopies in our center from July 2017 to December 2019, for eligibility for participation in this study,A total of 75 patients were excluded because of poor bowel preparation $(n=30)$, incomplete 
colonoscopy $(n=6)$, history of colonic polypectomy $(n=26)$, history of colectomy $(n=3)$, or diagnosis of polyposis $(n=2)$, colitis $(n=5)$, colorectal cancer $(n=3)$. Among the remaining 1794 patients, 419 patients consented to the study and were enrolled. Additional 9 patients were excluded for incomplete data collection and 410 patients ( 240 adenoma and 180 adenoma-free) were included in the final analysis. (Fig. 1)

\section{Measurements and definitions}

Demographic data and medical histories, including co-morbidities, smoking and drinking history, family history of malignant diseases, regular medications, frequency of physical exercises etc., of the patients was collected by patient interview and from a self-filling questionnaire. Current smoker was defined as smoking at least one cigarette per day for the previous 12 months ${ }^{8,9}$. Alcohol consumption was defined as drinking of over $140 \mathrm{~g}$ of alcohol per week ${ }^{8,9}$. Regular exercise was defined as exercise $\geq 3$ times per week (exercise was defined as walking, cycling, jogging or swimming for over 30 minutes a day) $)^{8,9}$. Regular aspirin use was defined as daily aspirin use for 3 months in the preceding 12 months. Family history of $\mathrm{CRC}$ was defined as $\mathrm{CRC}$ in $\geq 1$ first-degree relative at any age ${ }^{8,9}$.

Body fat of participants were measured by method of bioelectrical impedance analysis (BIA), using a machine InBody 220 (Inbody Co., Ltd, South Korea) (Fig. 2), which is widely used in worldwide for measurement of body composition. Many studies have reported the accuracy of BIA in measuring body composition is comparable to dual x-ray absorptiometry ${ }^{11}$ and air displacement plethysmography ${ }^{12}$. Body fat mass (BFM, kg), body fat percent (BFP, \%), and waist-to-hip fat ratio (\%) were recorded. Participant's blood pressure, height, weight, waist and hip circumference were measured. Blood parameters of metabolic syndrome, including fasting blood glucose (FBG), triglyceride (TG), cholesterol (CHOL), and high-density lipoprotein (HDL) were also measured.

$\mathrm{BMI}$ of participants were cataloged as: low (BMI $<18)$; normal $(18 \leq \mathrm{BMI} \leq 23.9)$; overweight $(24 \leq \mathrm{BMI} \leq$ $27.9)$; and obesity $(\mathrm{BMI} \geq 28)$ according to the Working Group on Obesity in China (WGOC) ${ }^{10}$. Metabolic syndrome (MetS) was defined according to the criteria of Adult Treatment Panel III and the Regional office for the Western Pacific Region of the World Health Organization (WPRO) as presence of 3 or more of the following 8,9 : central obesity (waist circumference $>90 \mathrm{~cm}$ in men and $>80 \mathrm{~cm}$ in women); blood pressure of $130 / 85 \mathrm{~mm} \mathrm{Hg}$ or higher or treatment for hypertension; FBG level of $6.1 \mathrm{mmol} / \mathrm{L}$ or higher or treatment with a glucose-lowering drug; triglyceride level of $1.69 \mathrm{mmol} / \mathrm{L}$ or higher; high-density lipoprotein cholesterol level less than $1.03 \mathrm{mmol} / \mathrm{L}$ in men and less than $1.29 \mathrm{mmol} / \mathrm{L}$ in women.

\section{Colonoscopy and histologic examination}

Colonoscopies were performed by experienced endoscopists or under supervision of experienced endoscopists who had performed more 1000 colonoscopies before year 2017 in our center. For colonic polyps, endoscopists performed polypectomy according to International standard. Tissue specimens were examined by two experienced pathologists independently. 


\section{Statistical analysis}

Continuous variables are expressed as means \pm SD (standard deviation). Categorical variables are expressed as numbers (percentage). For intergroup comparisons, continuous variables were analyzed by use of the Student's $t$ test or univariate analysis of variance, and categorical variables were analyzed by use the $\chi 2$ test or Fisher exact test. To identify risk factors independently associated with the occurrence of CRA, we conducted multivariate conditional logistic regression to measure the association between body adipose, components of metabolic syndrome and the presence of CRA, adjusting for sex, age, smoking, drinking, exercise, aspirin use and family history of CRC. All statistical tests were 2-sided, and a $p$ value of less than 0.05 was considered statistically significant. Statistical analysis was carried out with licensed copy of SPSS 22.0 (SPSS, Chicago, IL, USA).

\section{Results}

\section{Baseline characteristics of study participants}

From July 2017 to December 2019, a total of 410 participants (230 adenoma and 180 adenoma-free subjects) were analyzed. The mean age was 47 years (ranged $23-78$ years). Participants of adenoma group were older than adenoma-free group $(p<0.01)$ and more likely to be male $(p<0.01)$. With regard to smoking, drinking, exercise, aspirin use and family history of $\mathrm{CRC}$, there was no significant difference between adenoma and adenoma-free group in univariate analysis. BMI and waist circumference were both significantly higher in adenoma group $(p<0.01)$. Regarding data of body composition measured by BIA, body fat mass (BFM) and waist-to-hip fat ratio were higher in adenoma than adenoma-free group ( $p$ $<0.01$ ), while there was no significant difference in body fat percent (BFP) between the two groups $(p=$ 0.29). With respect to components of MetS, systolic BP, diastolic BP and FBG were higher in adenoma than adenoma-free group $(p<0.01)$, while no significant differences were demonstrated in TG and HDL-C between the two groups. (Table 1). 
Table 1

Basic characteristics of participants

\begin{tabular}{|c|c|c|c|}
\hline & $\begin{array}{l}\text { Adenoma-free } \\
(n=180)\end{array}$ & $\begin{array}{l}\text { Adenoma } \\
(n=230)\end{array}$ & $P$ value \\
\hline Mean age, y (SD) & $45.0(10.9)$ & $49.1(11.3)$ & $<0.01$ \\
\hline \multicolumn{4}{|c|}{ Demographic findings, no. of participants (\%) } \\
\hline Male sex & $78(43.3)$ & $136(59.1)$ & $<0.01$ \\
\hline Age $\leq 35$ & $36(20)$ & $25(10.9)$ & \multirow[t]{3}{*}{0.01} \\
\hline $36-59$ & $129(71.7)$ & $171(74.3)$ & \\
\hline$\geq 60$ & $15(8.3)$ & $34(14.8)$ & \\
\hline Current smoker ${ }^{a}$ & $19(10.6)$ & $35(15.2)$ & 0.17 \\
\hline Alcohol consumption ${ }^{\mathrm{b}}$ & $59(32.8)$ & $73(55.3)$ & 0.65 \\
\hline Family history of $\mathrm{CRC}^{\mathrm{C}}$ & $15(8.6)$ & $20(8.7)$ & 0.82 \\
\hline Regular exercise ${ }^{d}$ & $140(77.8)$ & $185(80.4)$ & 0.51 \\
\hline Aspirin ${ }^{\mathrm{e}}$ & $2(1.1)$ & $6(2.8)$ & 0.20 \\
\hline \multicolumn{4}{|c|}{ Measurement of obesity, mean (SD) } \\
\hline $\mathrm{BMI}, \mathrm{kg} / \mathrm{m}^{2}$ & $22.6(2.84)$ & $23.9(3.33)$ & $<0.01$ \\
\hline WC, $\mathrm{cm}$ & $80.0(12.1)$ & $83.9(11.4)$ & $<0.01$ \\
\hline \multicolumn{4}{|c|}{ Body fat measured by BIA, mean (SD) } \\
\hline $\mathrm{BFM}, \mathrm{kg}$ & $17.2(5.32)$ & $19.1(6.20)$ & $<0.01$ \\
\hline BFP, \% & $27.9(6.80)$ & $28.7(7.34)$ & 0.29 \\
\hline Waist-to-hip fat ratio, $\%$ & $0.88(0.06)$ & $0.91(0.06)$ & $<0.01$ \\
\hline
\end{tabular}

${ }^{a}$ Current smoker was defined as smoking at least one cigarette per day for the previous 12 months. ${ }^{b}$ Alcohol consumption was defined as drinking of over $140 \mathrm{~g}$ of alcohol per week. 'Family history of CRC was defined as CRC in more than one first degree relatives at any age. ${ }^{\mathrm{d}}$ Regular exercise was defined as exercise $\geq 3$ times per week. ${ }^{e}$ Regular aspirin use was defined as aspirin use for 3 months during the preceding 12 months.

$B M /$ body mass index, $W C$ waist circumference, $B F M$ body fat mass, $B F P$ body fat percent, $S B P$ systolic blood pressure, $D B P$ diastolic blood pressure, $F B G$ fasting blood glucose; $T G$ triglyceride, $H D L$ high-density lipoprotein. 


\begin{tabular}{|c|c|c|c|}
\hline & $\begin{array}{l}\text { Adenoma-free } \\
(n=180)\end{array}$ & $\begin{array}{l}\text { Adenoma } \\
(n=230)\end{array}$ & $P$ value \\
\hline $\mathrm{SBP}, \mathrm{mmHg}$ & $117(14.5)$ & $122(15.0)$ & $<0.01$ \\
\hline $\mathrm{DBP}, \mathrm{mmHg}$ & $72(10.6)$ & 76 (10.6) & $<0.01$ \\
\hline $\mathrm{FBG}, \mathrm{mmol} / \mathrm{L}$ & $5.0(0.80)$ & $5.23(0.86)$ & $<0.01$ \\
\hline $\mathrm{TG}, \mathrm{mmol} / \mathrm{L}$ & $1.46(0.98)$ & $1.57(1.03)$ & 0.27 \\
\hline $\mathrm{HDL}-\mathrm{C}, \mathrm{mmol} / \mathrm{L}$ & $1.25(0.28)$ & $1.26(0.32)$ & 0.91 \\
\hline \multicolumn{4}{|c|}{ 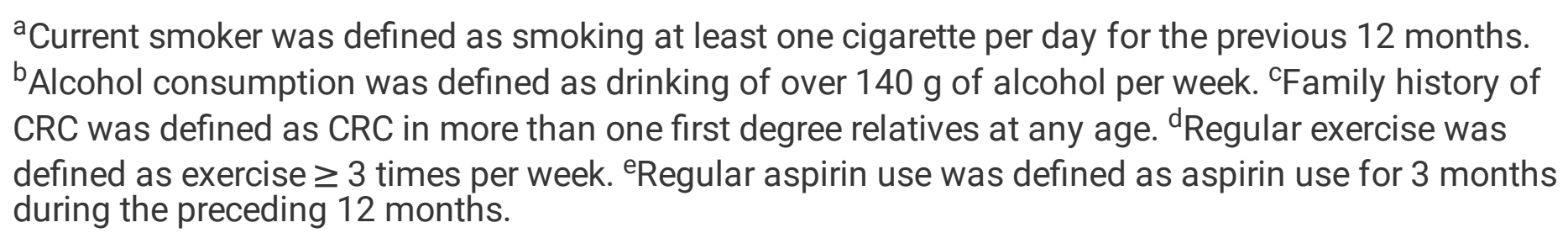 } \\
\hline
\end{tabular}

\section{Association of obesity and body adipose tissue measured by BIA with occurrence of CRA}

The association of body composition with occurrence of CRA was analyzed. In univariate analysis, overweight, obesity, and high waist-to-hip fat ratio were associated with occurrence of CRA. On multivariate logistic regression analysis (adjusted for age, sex, smoking, drinking, exercise, aspirin use, and family history of CRC), BMI is an independent risk factor for occurrence of CRA. The risks of CRA for participants of overweight (OR 1.68; 95\% Cl, 1.01-2.80; $\mathrm{p}<0.05)$ and obesity (OR 4.49; $95 \% \mathrm{Cl}, 1.37-14.7$; $p=0.01$ ) were much higher compared with participants of normal BMI. Waist-to-hip fat ratio measured by BIA is independently associated with occurrence of CRA, participants of high waist-to-hip fat ratio had a higher risk for CRA (OR 1.84; 95\% Cl, 1.09-3.09; $\mathrm{p}=0.02$ ). Whereas, BFM (as continuous variables) and BFP measured by BIA were not independently associated with occurrence of CRA on multivariate analysis, $p>0.05$. (Table 2). 
Table 2

Association of body fat measured by BIA with occurrence of CRA

\begin{tabular}{|c|c|c|c|c|c|c|}
\hline \multirow[t]{2}{*}{ Obesity index } & \multicolumn{2}{|c|}{ No. of participants (\%) } & \multicolumn{2}{|c|}{ Univariate analysis } & \multicolumn{2}{|l|}{$\begin{array}{l}\text { Multivariate } \\
\text { analysis }^{\mathrm{a}}\end{array}$} \\
\hline & $\begin{array}{l}\text { Adenoma- } \\
\text { free } \\
(n=180)\end{array}$ & $\begin{array}{l}\text { Adenoma } \\
(n=230)\end{array}$ & OR $(95 \% \mathrm{Cl})$ & $\begin{array}{l}\mathrm{P} \\
\text { value }\end{array}$ & OR $(95 \% \mathrm{Cl})$ & $\begin{array}{l}P \\
\text { value }\end{array}$ \\
\hline \multicolumn{7}{|l|}{$\mathrm{BMI}, \mathrm{kg} / \mathrm{m}^{2}$} \\
\hline Normal (18-23.9) & $114(63.3)$ & $\begin{array}{l}105 \\
(45.7)\end{array}$ & 1 & & 1 & \\
\hline Low $(<18)$ & $11(6.1)$ & $11(4.8)$ & $\begin{array}{l}1.02(0.66- \\
1.59)\end{array}$ & 0.92 & $\begin{array}{l}1.23(0.44- \\
3.49)\end{array}$ & 0.69 \\
\hline Overweight (24-27.9) & $51(28.3)$ & $94(40.9)$ & $\begin{array}{l}1.49(1.15- \\
1.94)\end{array}$ & 0.02 & $\begin{array}{l}1.68(1.01- \\
2.80)\end{array}$ & 0.04 \\
\hline Obesity ( $\geq 28$ ) & $4(2.2)$ & $20(8.7)$ & $\begin{array}{l}3.07(1.24- \\
7.58)\end{array}$ & $\begin{array}{l}< \\
0.01\end{array}$ & $\begin{array}{l}4.49(1.37- \\
14.7)\end{array}$ & 0.01 \\
\hline$P$ for trend & & & & $<.01$ & & 0.04 \\
\hline \multicolumn{7}{|l|}{ BFP, \% } \\
\hline $\begin{array}{l}\text { Normal (M: 10-20; F: } \\
\text { 18-28) }\end{array}$ & $60(33.3)$ & $63(27.4)$ & 1 & & 1 & \\
\hline Low & $2(1.1)$ & $2(0.9)$ & $\begin{array}{l}0.97(0.36- \\
2.62)\end{array}$ & 0.93 & $\begin{array}{l}0.75(0.42- \\
1.34)\end{array}$ & 0.33 \\
\hline High & $118(65.6)$ & $\begin{array}{l}165 \\
(71.7)\end{array}$ & $\begin{array}{l}1.15(0.94- \\
1.40)\end{array}$ & 0.18 & $\begin{array}{l}0.96(0.09- \\
10.5)\end{array}$ & 0.97 \\
\hline$P$ for trend & & & & 0.41 & & 0.62 \\
\hline \multicolumn{7}{|l|}{ Waist-to-hip fat ratio, $\%$} \\
\hline $\begin{array}{l}\text { Normal (M:0.8-0.9; F: } \\
0.75-0.85)\end{array}$ & $85(47.2)$ & $81(57.1)$ & 1 & & 1 & \\
\hline Low & $3(1.7)$ & $4(1.7)$ & $\begin{array}{l}1.14(0.59- \\
2.20)\end{array}$ & 0.72 & $\begin{array}{l}1.00(0.18- \\
5.62)\end{array}$ & 0.99 \\
\hline High & $92(51.1)$ & $\begin{array}{l}145 \\
(63.0)\end{array}$ & $\begin{array}{l}1.22(1.02- \\
1.47)\end{array}$ & 0.02 & $\begin{array}{l}1.84(1.09- \\
3.09)\end{array}$ & 0.02 \\
\hline
\end{tabular}

${ }^{a}$ Adjusted for age (continuous variable), sex, smoking, alcohol consumption, exercise, aspirin, and family history of CRC

$M$ male, $F$ female, $B M I$ body mass index, $B F P$ body fat percent 


\begin{tabular}{|c|c|c|c|c|c|c|}
\hline \multirow[t]{2}{*}{ Obesity index } & \multicolumn{2}{|c|}{ No. of participants (\%) } & \multicolumn{2}{|c|}{ Univariate analysis } & \multicolumn{2}{|l|}{$\begin{array}{l}\text { Multivariate } \\
\text { analysis }^{\mathrm{a}}\end{array}$} \\
\hline & $\begin{array}{l}\text { Adenoma- } \\
\text { free } \\
(n=180)\end{array}$ & $\begin{array}{l}\text { Adenoma } \\
(n=230)\end{array}$ & OR $(95 \% \mathrm{Cl})$ & $\begin{array}{l}P \\
\text { value }\end{array}$ & OR $(95 \% \mathrm{Cl})$ & $\begin{array}{l}P \\
\text { value }\end{array}$ \\
\hline$P$ for trend & & & & 0.05 & & 0.35 \\
\hline \multicolumn{7}{|c|}{$\begin{array}{l}\text { aAdjusted for age (continuous variable), sex, smoking, alcohol consumption, exercise, aspirin, and } \\
\text { family history of CRC }\end{array}$} \\
\hline \multicolumn{7}{|c|}{$M$ male, $F$ female, $B M /$ body mass index, $B F P$ body fat percent } \\
\hline
\end{tabular}

\section{Association of MetS with occurrence of CRA.}

In univariate analysis, MetS and all of its five components except high TG and low HDL-C were associated with occurrence of CRA. However, on multivariate logistic regression analysis (adjusted for age, sex, smoking, drinking, exercise, aspirin use, and family history of CRC), only central obesity (waist circumference $>90 \mathrm{~cm}$ in men and $>80 \mathrm{~cm}$ in women) is an independent risk factor for occurrence of CRA. Participant of central obesity had a similarly 2-fold risk for CRA than participants without central obesity (OR 1.90; 95\% $\mathrm{Cl} 1.17-3.08 ; \mathrm{p}=0.01)$. Whereas, other components of Mets were not independently associated with occurrence of CRA. (Table 3 ) 
Table 3

Association of metabolic syndrome with occurrence of CRA

\begin{tabular}{|c|c|c|c|c|c|c|}
\hline \multirow[t]{2}{*}{$\begin{array}{l}\text { Components of metabolic } \\
\text { syndrome }\end{array}$} & \multicolumn{2}{|c|}{ No. of participants (\%) } & \multicolumn{2}{|c|}{ Univariate analysis } & \multicolumn{2}{|l|}{$\begin{array}{l}\text { Multivariate } \\
\text { analysis }{ }^{a}\end{array}$} \\
\hline & $\begin{array}{l}\text { Adenoma- } \\
\text { free } \\
(n=180)\end{array}$ & $\begin{array}{l}\text { Adenoma } \\
(n=230)\end{array}$ & OR $(95 \% \mathrm{Cl})$ & $\begin{array}{l}P \\
\text { value }\end{array}$ & OR $(95 \% \mathrm{Cl})$ & $\begin{array}{l}P \\
\text { value }\end{array}$ \\
\hline High BP & $29(16.1)$ & $69(30.0)$ & $\begin{array}{l}1.65 \\
(1.18- \\
2.30)\end{array}$ & $\begin{array}{l}< \\
0.01\end{array}$ & $\begin{array}{l}1.59(0.88- \\
2.76)\end{array}$ & 0.12 \\
\hline High WC ${ }^{c}$ & $49(27.2)$ & $\begin{array}{l}110 \\
(43.5)\end{array}$ & $\begin{array}{l}1.49 \\
(1.15- \\
1.94)\end{array}$ & $\begin{array}{l}< \\
0.01\end{array}$ & $\begin{array}{l}1.90(1.17- \\
3.08)\end{array}$ & 0.01 \\
\hline $\mathrm{TG} \geq 1.69 \mathrm{mmol} / \mathrm{L}$ & $55(30.6)$ & $90(39.1)$ & $\begin{array}{l}1.24 \\
(0.96- \\
1.58)\end{array}$ & 0.07 & $\begin{array}{l}1.06(0.68- \\
1.82)\end{array}$ & 0.83 \\
\hline $\mathrm{FBG} \geq 6.1 \mathrm{mmol} / \mathrm{L}$ & $11(6.1)$ & $33(14.3)$ & $\begin{array}{l}1.81 \\
(1.07- \\
3.06)\end{array}$ & 0.01 & $\begin{array}{l}1.80(0.81- \\
4.49)\end{array}$ & 0.18 \\
\hline Low HDL-C ${ }^{d}$ & $74(41.1$ & $82(35.7)$ & $\begin{array}{l}0.90 \\
(0.72- \\
1.12)\end{array}$ & 0.26 & $\begin{array}{l}0.71(0.43- \\
1.10)\end{array}$ & 0.15 \\
\hline Metabolic syndrome $e^{\mathrm{e}}$ & $23(12.8)$ & $56(24.3)$ & $\begin{array}{l}1.60 \\
(1.11- \\
2.30)\end{array}$ & $\begin{array}{l}< \\
0.01\end{array}$ & $\begin{array}{l}1.13(0.48- \\
2.634)\end{array}$ & 0.78 \\
\hline
\end{tabular}

aAdjusted for age (continuous variable), sex, smoking, alcohol consumption, exercise, aspirin, and family history of CRC.

${ }^{b}$ Blood pressure of $130 / 85 \mathrm{~mm} \mathrm{Hg}$ or greater or use of antihypertensive drug.

'Waist circumference greater than $90 \mathrm{~cm}$ in men, greater than $80 \mathrm{~cm}$ in women.

${ }^{\mathrm{d}} \mathrm{HDL}-\mathrm{C}$ less than $1.03 \mathrm{mmol} / \mathrm{L}$ in men, less than $1.29 \mathrm{mmol} / \mathrm{L}$ in women.

e Metabolic syndrome was defined as fulfilled at least 3 of the fine components.

$B P$ diastolic blood pressure, $W C$ waist circumference, $T G$ triglyceride, $F B G$ fasting blood glucose; $H D L$ high-density lipoprotein.

\section{Discussion}

In accordance with previous publications, our study demonstrated obesity is an independent risk factor for occurrence of $\mathrm{CRA}^{13}$. After adjusted by age, sex, smoking, etc, overweight or obesity had 1.7-fold or 4.5-fold increased risks for occurrence of CRA respectively, compared with people of normal body weight. 
Overweight or obesity, according to the world health organization (WHO), are defined as excessive fat accumulation in body which may have negative effects on general health ${ }^{9}$. There are two types of obesity according to the location of body fat accumulation, peripheral or central (or named visceral) obesity. Peripheral obesity means excessive adipose tissue accumulates mainly in body trunk, while central (or named visceral) obesity means excessive adipose tissue accumulates in abdominal cavity, including adipose of omentum, or mesentery. Studies have demonstrated that visceral obesity is much more harmful than peripheral obesity ${ }^{14-16}$. Waist circumference is a clinical simple, but rough surrogate marker for prediction of visceral adipose depositions. Scientists have tried different approaches to estimate the content of visceral fat precisely. Some reports the use of abdominal ultrasonography for assessment of visceral adiposity, however the accuracy is disappointing and ultrasonography is not more reliable than simple waist circumference in assessing visceral fat. ${ }^{17,18}$ Some proposed calculating the area of intraabdominal fat tissue by abdominal CT scan. ${ }^{8,19}$ Although the data calculated under CT scan may be more accurate, the irradiation and high cost limits its applications in clinical practice or studies.

Bioelectrical impedance analysis (BIA) is a noninvasive tool for analysis of body composition. Human body is composed of conductors and nonconductors. Water accounts for $50-70 \%$ of the human body and is good conductor. While the water content is different in fat, muscle and skeleton, which accounts for the different impedance when electric circuits passed. BIA predicts fat tissue by measuring body impedance when a low-frequency current travels through the body. Mechanism of BIA in predicting total body water (TBW) is by calculating data in a formula: TBW $=0.377 \mathrm{H} 2 / \mathrm{R}+0.14 \mathrm{~W}-0.08 \mathrm{~A}+2.9(\mathrm{M})+4.65$ $(H$, height; $R$, resistance; $W$, weight; $A$, age; $M$, male). The machine Inbody 220 used in this study uses multiple frequencies (from $1 \mathrm{KHZ}$ to $1 \mathrm{MHz}$ ) and detects fine section of body (left/right arm, left/right leg, trunk) separately, which makes it more precise than traditional BIA machines and can get result of waistto-hip fat ratio. It is widely used in worldwide clinical practice nowadays. Many studies have demonstrated the accuracy of Inbody machine in measuring body composition compared to other methods like dual $x$-ray absorptiometry ${ }^{20,21}$ or Computed Tomography ${ }^{22}$.

Some previous studies have reported the association of body composition with occurrence of colorectal adenoma. Almendingen $\mathrm{K}$, et al. ${ }^{23}$ reported colorectal adenoma growth was highly associated with increasing levels of triceps skinfold thickness (TSF), BFP, and BMI, in a small prospective study of 62 agematched participants with 3 yrs. of follow-up. Whereas, Frantz DJ et. al. ${ }^{24}$ reported a negative relationship between BFP and status of CRA in a cross-sectional comparative study of 934 participants. In these two previous studies, the authors had not reported the relationship between the distribution of body fat and occurrence of CRA, for the BIA machines used in their studies did not have the function of calculating data of waist-to-hip fat ratio by measuring the fat of trunk and limbs separately. In this study, body composition of participants was measured by a machine Inbody 220, which can measure fat content of trunk and limbs separately and get data of waist-to-hip fat ratio. Results showed that after adjustment for the confounders, high waist-to-hip fat ratio measured by BIA is independently associated with CRA, whereas body fat mass and body fat percent were not associated with CRA, 
The metabolic syndrome (MetS) $)^{8,9}$ is a complex disease condition characterized by the constellation of glucose intolerance, obesity, hypertension, and dyslipidemia. The definition of MetS proposed by the WHO serves as a reminder of high risks of developing cardiovascular diseases and death in MetS. As MetS shared some risk factors of CRA, including obesity, lack of exercise, red meat diet, etc., MetS is supposed to be associated with development of CRA. Some studies have showed that MetS was associated with occurrence of CRA. ${ }^{25,26}$ In this study, MetS and its individual components including hypertension, diabetes, hyperlipidemia, were higher in participants of adenoma than adenoma-free groups in univariate analysis. However, only high waist circumference was an independent risk factor for CRA after adjusting for the confounder in a multivariate analysis, suggesting that central obesity is the core factor of MetS in its relationship with CRA.

Visceral fat accumulation is a main anatomical feature of central obesity. Visceral fat has been discovered as an endocrine organ producing a variety of proteins, hormones and cytokines that are referred as adipokines ${ }^{27}$. The underlying mechanism in the positive association of central obesity with CRA may be because of the imbalance of adipokines produced by visceral fat. The adipokines possess broad biological activities, including homeostatic and pathologic functions. Visceral fat deposition increases the release of proinflammatory adipokines including IL-6, leptin and TNF-a, which accompanied with decreased release of anti-inflammatory adipokines, like adiponectin ${ }^{28}$. The imbalance of adipokines will contribute to a process of carcinogenesis, promoting development of kinds of tumors ${ }^{29}$. Meanwhile, visceral obesity is associated with hyperinsulinemia and elevated triglyceride levels ${ }^{30}$. Hyperinsulinemia induces an increase in insulin-like growth factor-1 (IGF-1), which will create a favorable milieu for carcinogenesis by promoting cell proliferation and inhibiting apoptosis.

Our study demonstrated that body fat distribution measured by BIA is associated with occurrence of CRA. Visceral obesity is a risk factor for development of CRA. BIA could be a good clinical tool for assessment of visceral obesity to predict risk of development of CRA. Some limitations of this study should be noted. First, this is a retrospective case control study but not a cross-sectional study, which may exist selection bias of participants. Second, the sample size was relatively small thus it was difficult to perform stratified analysis by sex. Some studies reported that the risk of obesity for CRA was different in the two different sex. Third, the study was not designed to measure serum biochemical biomarkers like adipokine or insulin-like growth factors (IGFs) of participants, therefore we cannot analyze the potential mechanisms underlying the association of visceral obesity with development of CRA.

\section{Conclusion}

In summary, our study found a significant correlation between the waist-to-hip fat ratio measured by BIA and occurrence of CRA, confirming that visceral adiposity was associated with CRA formation in Chinese population. Our findings indicate that BIA could be a non-invasive tool for stratifying risk of CRA in clinical use. Screening colonoscopy should be enhanced for people of visceral obesity to early detect and remove CRA and therefore prevent development of colorectal cancer. 


\section{Abbreviations}

CRC Colorectal Cancer, CRA colorectal adenoma, BIA Bioelectrical impedance analysis, BMI body mass index, WC waist circumference, BFM body fat mass, BFP body fat percent, SBP systolic blood pressure, DBP diastolic blood pressure, MetS metabolic syndrome, FBG fasting blood glucose, TG triglyceride, CHOL cholesterol, HDL high-density lipoprotein

\section{Declarations}

\section{Ethics approval and consent to participate:}

The study was approved by Institutional Review Board at the University of Hong Kong-Shenzhen Hospital (IRB Number: [2016] 30). Written consents were obtained for all participants. This study was carried out according to the ethical principles for medical research involving human subjects-the Declaration of Helsinki of World Medical Association.

\section{Availability of data and materials:}

All data generated or analyzed during this study are included in this published article and its supplementary information files.

\section{Competing interests:}

The authors declare that they have no competing interests.

\section{Funding:}

This work was supported by a grant to Zhong-Hui Liu from the Shenzhen Healthcare Research Project of China (grant number: SZFZ2017079). The funding organization played no role in the design and conduct of the study, in the collection, management, analysis, and interpretation of the data, or in the preparation, review, or approval of the manuscript.

\section{Authors' contributions:}

JKM Fan and ZH Liu conceived and designed the experiments; ZH Liu, GX Zhang, H Zhang, L Jiang, Y Deng, JW Liu and XF Yang performed the experiments; ZH Liu and FSY Chan analyzed the data; JKM Fan supervised and administrated the project; ZH Liu, FSY Chan, and JKM Fan wrote the paper. All authors agreed with the manuscript's results and conclusions.

\section{Acknowledgements:}


None.

\section{References}

1. Global Burden of Disease Cancer Collaboration. The Global Burden of Cancer 2013. JAMA Oncol. 2015; 1: 505-27.

2. Sievers CK, Zou L, Pickhardt PJ, et al. Modeling the rise of intratumoral heterogeneity in growing, static, and regressing human colorectal polyps. Cancer Research Supplement. 2016: 151-151;

3. Cho KR, Vogelstein B. Genetic alterations in the adenoma-carcinoma sequence. Cancer. 1992; 70: 1727-31

4. Winawer SJ, Zauber AG, Ho MN, et al. Prevention of colorectal cancer by colonoscopic polypectomy. The National Polyp Study Workgroup. N Engl J Med. 1993; 329:1977-81

5. Marres CCM, Buskens CJ, Schriever E, et al. The impact of the national bowel screening program in the Netherlands on detection and treatment of endoscopically unresectable benign polyps, Tech Coloproctol. 2017 Nov;21(11):887-891. doi: 10.1007/s10151-017-1705-x

6. Aran V, Victorino AP, Thuler LC, et al. Colorectal Cancer: Epidemiology, Disease Mechanisms and Interventions to Reduce Onset and Mortality. Clin Colorectal Cancer. 2016; 15(3): 195-203. doi: 10.1016/j.clcc.2016.02.008.

7. Bardou M, Barkun AN, Martel M. Obesity and colorectal cancer. Gut. 2013; 62(6): 933-47. doi: 10.1136/gutjnl-2013-304701.

8. Hyoun Woo Kang, Donghee Kim, Hwa Jung Kim, et al. Visceral obesity and insulin resistance as risk factors for colorectal adenoma: A cross-sectional case-control study, Am J Gastroenterol 2010; 105:178-187; doi:10.1038/ajg.2009.541

9. Su Youn Nam, Byung Chang Km, Kyung Su Han, et al. Abdominal visceral adipose tissue predicts risk of colorectal adenoma in both sexes, Clinical Gastroenterology and Hepatology, 2010;8:443-450

10. Zhang L, Wang Z, Wang X, et al. Prevalence of overweight and obesity in China: Results from a crosssectional study of 441 thousand adults, 2012-2015. Obes Res Clin Pract, 2020; S1871-403X (19)30764-1. doi: 10.1016/j.orcp.2020.02.005.

11. Thomson R, Brinkworth GD, Buckley JD, et al. Good agreement between bioelectrical impedance and dual-energy $\mathrm{X}$-ray absorptiometry for estimating changes in body composition during weight loss in overweight young women, Clin Nutr. 2007 Dec;26(6):771-7

12. Steinberg A, Manlhiot C, Li P, et al. Development and Validation of Bioelectrical Impedance Analysis Equations in Adolescents with Severe Obesity, J Nutr. 2019 Jul 1;149(7):1288-1293. doi: 10.1093/jn/nxz063

13. Omata F, Deshpande GA, Ohde S, et al. The association between obesity and colorectal adenoma: systematic review and meta-analysis. Scand J Gastroenterol. 2013; 48(2): 136-46. doi: $10.3109 / 00365521.2012 .737364$. 
14. Streng KW, Voors AA, Hillege HL, et al. Waist-hip ratio and mortality in heart failure. Eur J Heart Fail, 2018; 20(9): 1269-1277;

15. Caspard H, Jabbour S, Hammar N, et al. Recent trends in the prevalence of type 2 diabetes and the association with abdominal obesity lead to growing health disparities in the USA: An analysis of the NHANES surveys from 1999 to 2014. Diabetes Obes Metab, 2018; 20(3): 667-671;

16. LeBlanc ES, Patnode CD, Webber EM, et al. Behavioral and pharmacotherapy weight loss interventions to prevent obesity-related morbidity and mortality in adults: updated evidence report and systematic review for the US preventive services task force, JAMA. 2018; 18; 320(11):1172-1191

17. Gong $W$, Ren $H$, Tong $H$, et al. A comparison of ultrasound and magnetic resonance imaging to assess visceral fat in the metabolic syndrome, Asia Pac J Clin Nutr, 2007;16 Suppl 1:339-45

18. Koot $B G$, Westerhout $R$, Bohte $A E$, et al. Ultrasonography is not more reliable than anthropometry for assessing visceral fat in obese children. Pediatr Obes. 2014; 9(6):443-7. doi: 10.1111/j.20476310.2013. 00193.x

19. Jong Pil Im, Donghee Kim, Su Jin Chung, Visceral obesity as a risk factor for colorectal adenoma occurrence in surveillance colonoscopy, Gastrointest Endosc 2018; 88: 119-27

20. Khan S, Xanthakos SA, Hornung L, et al. Relative Accuracy of Bioelectrical Impedance Analysis for Assessing Body Composition in Children with Severe Obesity, J Pediatr Gastroenterol Nutr. 2020 Feb 19. doi: $10.1097 /$ MPG. 0000000000002666

21. Lee SY, Ahn S, Kim YJ, et al. Comparison between Dual-Energy X-ray Absorptiometry and Bioelectrical Impedance Analyses for Accuracy in Measuring Whole Body Muscle Mass and Appendicular Skeletal Muscle Mass, 2018 Jun 7;10(6). pii: E738. doi: 10.3390/nu10060738.

22. Kim EY, Kim SR, Won DD, et al. Multifrequency Bioelectrical Impedance Analysis Compared With Computed Tomography for Assessment of Skeletal Muscle Mass in Primary Colorectal Malignancy: A Predictor of Short-Term Outcome After Surgery, Nutr Clin Pract. 2019 Jun 24. doi: 10.1002/ncp.10363.

23. Almendingen $\mathrm{K}$, Hofstad $\mathrm{B}$, Vatn $\mathrm{MH}$. Does high body fatness increase the risk of presence and growth of colorectal adenomas followed up in situ for 3 years? Am J Gastroenterol. 2001; 96(7): 2238-46.

24. Frantz DJ, Crockett SD, Galanko JA, et al. Percent body fat measured by bioelectrical impedance is not associated with colorectal adenoma status, J Gastroenterol Hepatol Res. 2013; 2(3): 445-448

25. Kim JH, Cho KI, Kim YA, et al. Elevated Neutrophil-to-Lymphocyte Ratio in Metabolic Syndrome Is Associated with Increased Risk of Colorectal Adenoma. Metab Syndr Relat Disord;2017 Oct;15(8):393-399

26. Kim BC, Shin A, Hong CW, et al. Association of colorectal adenoma with components of metabolic syndrome. Cancer Causes Control. 2012; 23:727-735

27. Balistreri CR, Caruso C, Candore G, The role of adipose tissue and adipokines in obesity-related inflammatory diseases. Mediators Inflamm. 2010: 802078. doi: 10.1155/2010/802078 
28. Lyon CJ, Law RE, Hsueh WA, Minireview: adiposity, inflammation, and atherogenesis. Endocrinology, 2003; 144: 2195-2200

29. Coussens LM, Zitvogel L, Palucka AK, et al. Neutralizing tumor-promoting chronic inflammation: a magic bullet? Science, 2013; 339: 286-291

30. Nam SY. Obesity-related digestive diseases and their pathophysiology. Gut Liver, 2017; 11:323-34

\section{Figures}

Asymptomatic patient who underwent colonoscopy at the University of Hong Kong-Shenzhen Hospital from 2017 to 2109 ( $n=1869)$

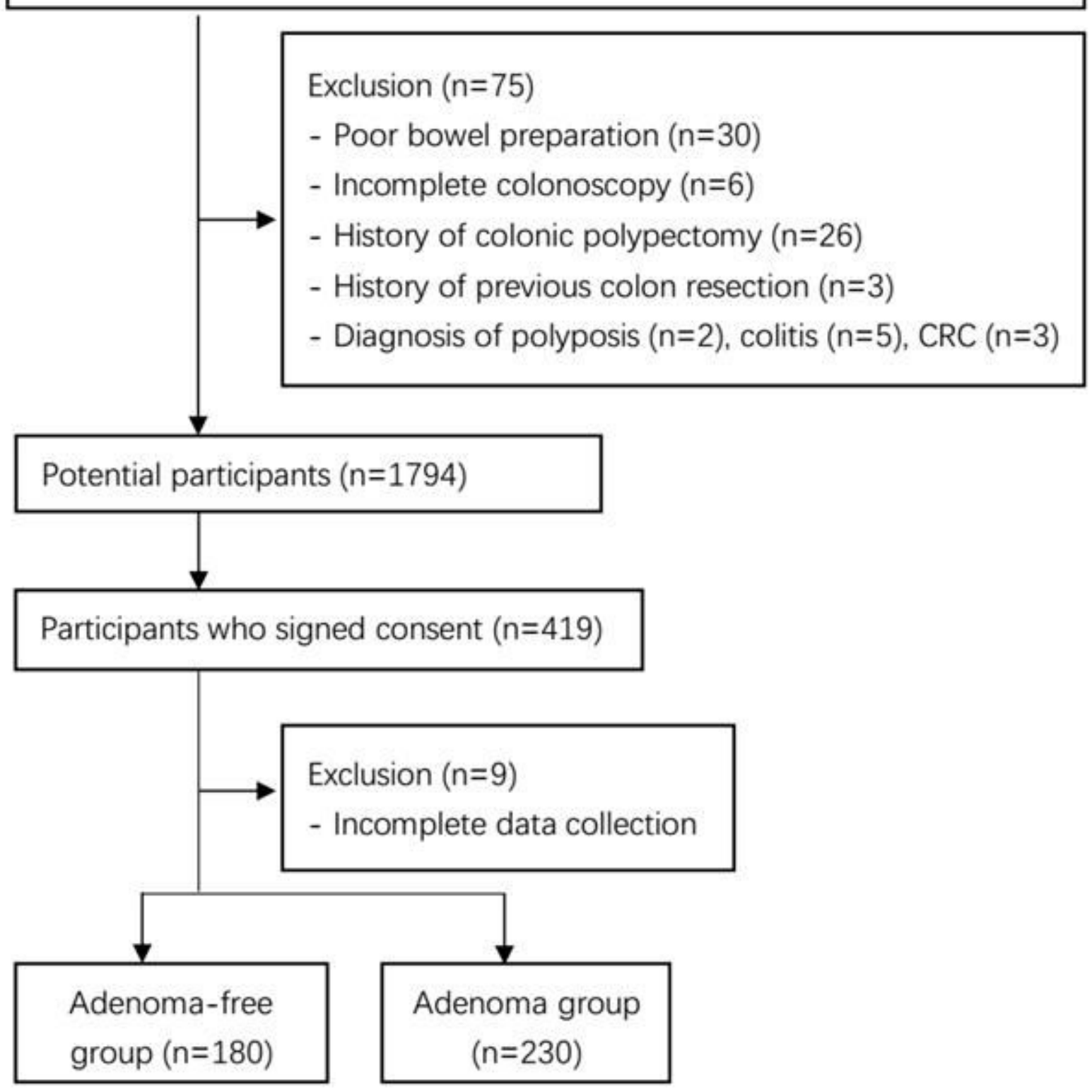

Figure 1

Flow chart showing the enrollment process of the study cohort. 


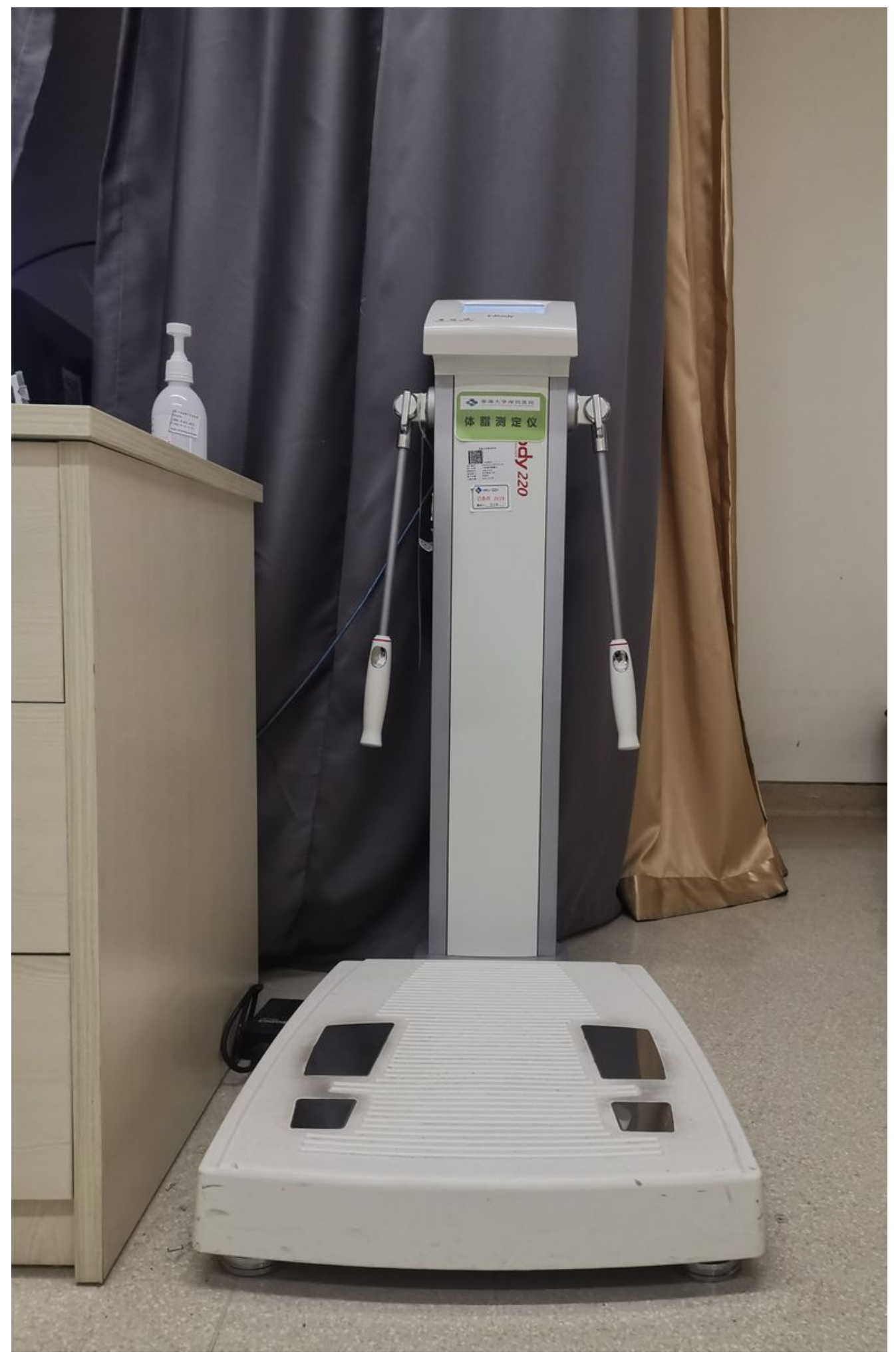

Figure 2

The machine InBody 220 (Biospace Co., South Korea) used for measurement of body composition in this study.

\section{Supplementary Files}


This is a list of supplementary files associated with this preprint. Click to download.

- Databaseofparticipants.xlsx 